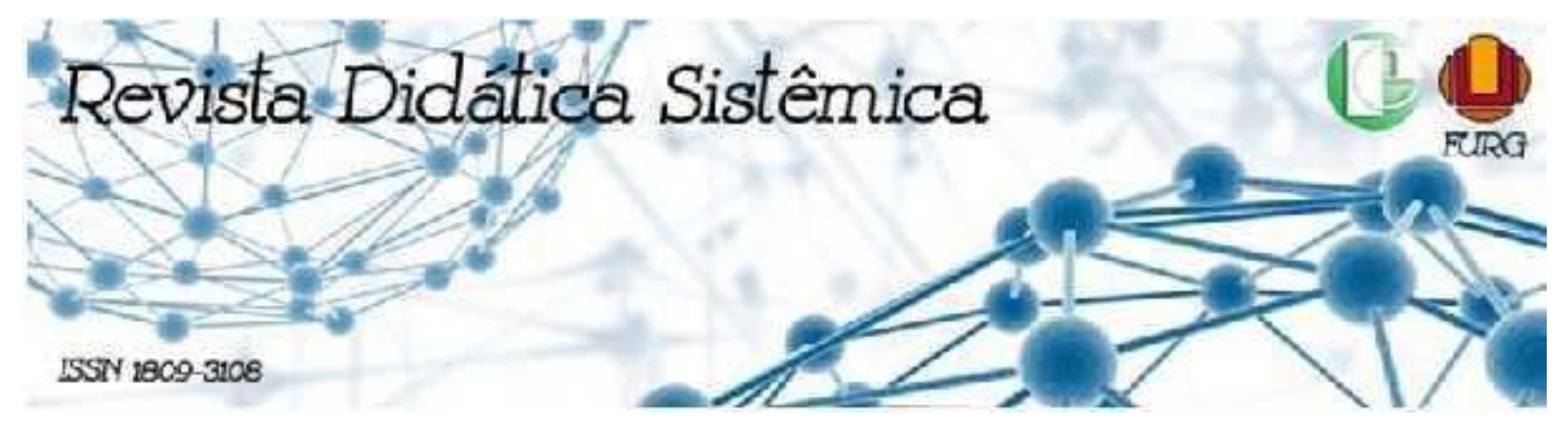

\title{
EDUCAÇÃO FÍSICA E EDUCAÇÃO INFANTIL: UM PROJETO PEDAGÓGICO INTEGRADO E INTERDISCIPLINAR
}

Renata de Moraes Lino ${ }^{1}$ Ingrid Dittrich Wiggers ${ }^{2}$

\section{RESUMO}

$\mathrm{O}$ artigo discorre sobre um projeto pedagógico desenvolvido, colaborativamente, por professores de atividades e de educação física, no âmbito da Educação Infantil, em uma instituição pública do Distrito Federal. O objetivo é descrever essa experiência, assim como analisá-la à luz de elementos teóricos do campo da educação física e da educação. Como escolha metodológica, utilizou-se a pesquisa pedagógica, provocando o grupo de professores à construção de um projeto organizado por meio de ações integradas e interdisciplinares. O projeto abordou a tríade "alimentação, higiene e valores", mediada pela literatura infantil, que norteou as atividades voltadas às crianças. Em paralelo, organizamos um grupo de formação entre esses professores, que subsidiou o desenvolvimento de todas as etapas do projeto. Destacamos o diálogo e o trabalho coletivo ao longo do processo e identificamos que a interdisciplinaridade representa uma perspectiva heurística para a atuação docente na Educação Infantil.

Palavras-chave: Educação Física Escolar; Educação Infantil; Interdisciplinaridade; Programa Educação com Movimento.

\section{PHYSICAL EDUCATION AND CHILDHOOD EDUCATION: AN INTEGRATED AND INTERDISCIPLINARY PEDAGOGICAL PROJECT}

\begin{abstract}
This article discusses a pedagogical project developed collaboratively by teachers and physical education teachers, within the scope of Childhood Education, in a public institution in the Federal District, in Brazil. The objective is to describe this experience, as well as analyse it in the light of theoretical elements in the field of physical education and education. As a methodological choice, pedagogical research was used, causing the group of teachers to build a project organized through integrated and interdisciplinary actions. This project discussed the triad "food, hygiene and values", mediated by children's literature, which guided the activities aimed at children. In parallel, we organized a training group among these teachers, which subsidized the development of all of the stages of the project. We highlight the dialogue and collective work throughout this process and identified that interdisciplinarity represents a heuristic perspective for the teaching performance in Childhood Education.
\end{abstract}

Keywords: Physical Education; Childhood Education; Interdisciplinarity; Education with Movement Program.

\footnotetext{
${ }^{1}$ Professora da Secretaria de Estado de Educação do Distrito Federal, Mestre em Educação Física pela Universidade de Brasília, Integrante do Imagem - Grupo de Pesquisa sobre Corpo e Educação, renatinhamlino@gmail.com.

${ }^{2}$ Professora Titular da Universidade de Brasília, Doutora em Educação pela Universidade Federal de Santa Catarina, Coordenadora do Imagem - Grupo de Pesquisa sobre Corpo e Educação, ingridwiggers@gmail.com.
} 


\section{EDUCACIÓN FÍSICA Y EDUCACIÓN INFANTIL: UN PROYECTO PEDAGÓGICO INTEGRADO E INTERDISCIPLINARIO}

\section{RESUMEN}

El artículo reflexiona acerca de un proyecto pedagógico desarrollado colaborativamente por docentes de la educación primaria y la educación física, en el ámbito de la Educación Infantil, en una institución pública del Distrito Federal, en Brasil. El objetivo es describir esta experiencia y analizarla a la luz de elementos teóricos del campo de la educación física y de la educación. Como elección metodológica, se utilizó la investigación pedagógica, impulsando al grupo de docentes a la construcción de un proyecto organizado por medio de acciones integradas e interdisciplinarias. El proyecto abordó la tríada "alimentación, higiene y valores", mediada por la literatura infantil, que guio las actividades dirigidas a niños. En paralelo, organizamos un grupo de formación entre esos docentes, que contribuyó al desarrollo de todas las etapas del proyecto. Destacamos el diálogo y el trabajo colectivo a lo largo del proceso e identificamos que la interdisciplinariedad representa una perspectiva heurística para la actuación docente en la Educación Infantil.

Palabras clave: Educación Física Escolar; Educación Infantil; Interdisciplinariedad; Programa Educación con Movimiento.

\section{INTRODUÇÃO}

Neste trabalho, apresentamos um projeto pedagógico promovido junto a um grupo de professores da Educação Infantil (EI), visando à concretização de ações pedagógicas integradas e interdisciplinares no dia a dia escolar. Os professores envolvidos, nessa intervenção, foram os de atividades ${ }^{3}$ e de educação física, atuantes em uma instituição da Secretaria de Estado de Educação do Distrito Federal (SEEDF). Por meio de um grupo de formação, os professores foram provocados a construir, coletivamente, um projeto pedagógico para ser realizado durante o primeiro semestre letivo de $2019 .{ }^{4}$

Ao levantar o tema de um projeto pedagógico de caráter integrado e interdisciplinar, torna-se relevante a discussão sobre o "papel do professor" no contexto da EI. O debate pode ser gerado na medida em que nos perguntamos: qual a formação desse profissional? Apenas os pedagogos devem estar presentes na EI? É possível a incorporação de professores de outras áreas de conhecimento? Silva e Arce (2010) destacam que esse profissional precisa elaborar uma competência polivalente. O professor da EI deve saber desenvolver, com suas crianças, conteúdos de naturezas diversas, que abrangem desde cuidados essenciais até conhecimentos específicos, oriundos das diversas áreas do conhecimento. É um profissional que precisa atuar, necessariamente, de forma integrada e interdisciplinar.

\footnotetext{
${ }^{3}$ A nomenclatura professor de "atividades" refere-se ao professor graduado em pedagogia. Trata-se de um termo usual entre os professores da SEEDF e utilizado, também, em documentos oficiais dessa instituição educacional.

${ }^{4}$ A pesquisa foi aprovada pelo Comitê de Ética em Ciências da Saúde da UnB, Processo no ${ }^{\circ}$. 3.901.098.
} 
Sendo assim, delimitamos, como objetivo, descrever e analisar um projeto pedagógico desenvolvido, colaborativamente, por professores de atividades e de educação física, no âmbito da EI, em uma instituição pública do Distrito Federal (DF). Do ponto de vista metodológico, o estudo se estruturou como uma investigação de abordagem qualitativa. Optamos pelos fundamentos da pesquisa pedagógica, que se caracteriza, conforme Lankshear e Knobel (2008), por professores realizando pesquisas pertinentes à sua própria prática profissional. Tais estudos são demarcados por um contexto real da escola, das problemáticas e das inquietações relacionadas às suas ações pedagógicas.

Organizamos as próximas seções do artigo da seguinte forma. Inicialmente, destacamos algumas referências sobre a EI, bem como sobre o Programa Educação com Movimento, que norteia a atuação do professor de Educação Física, na EI, na rede pública do DF. Em seguida, estabelecemos uma descrição e uma análise do projeto pedagógico desenvolvido com as crianças, abrangendo, também, o grupo de formação com os professores. Por último, em nossas considerações finais, apontamos perspectivas para uma atuação conjunta entre os profissionais da EI.

\section{A EDUCAÇÃO FÍSICA NA EDUCAÇÃO INFANTIL NO DISTRITO FEDERAL}

A educação física é reconhecida como componente curricular para toda a educação básica desde a Lei de Diretrizes e Bases da Educação Nacional (LDBEN), de 1996. No ano de 2001, houve o acréscimo do termo "obrigatório" a esse componente. Essa alteração do texto do artigo 26, inciso $3^{\circ}$, da Lei $n^{\circ}$ 9394/96, refletiu em uma tentativa de reforçar a exigência legal que já existia. Na primeira redação da Lei, embora a educação física estivesse inscrita como componente curricular, no caso da EI e anos iniciais, dava-se margem para uma interpretação que permitia que sua realização fosse incorporada ao trabalho dos professores pedagogos ou do magistério (IMPOLCETTO; DARIDO, 2020; MAGALHÃES; KOBAL; GODOY, 2007).

A atuação do professor de educação física, na EI, ainda que seja obrigatória por lei federal, depende de políticas públicas municipais e estaduais que viabilizem a inserção desse profissional nessa etapa do ensino. O programa de inserção do professor de educação física, na EI e nos anos iniciais do Ensino Fundamental, no DF, chama-se Programa Educação com Movimento (PECM). É um programa que, além de propor e desenvolver aspectos específicos da educação física como a cultura corporal, busca uma parceria com o professor de atividades nas diversas ações pedagógicas da escola, aspirando contribuir para a formação de valores sociais. 
Dessa forma, são estimuladas ações pedagógicas integradas e interdisciplinares entre os professores de educação física e de atividades. No âmbito das ações integradas, destacam-se o planejamento, a execução e a avaliação. Por sua vez, as áreas de conhecimento e as possibilidades de articulação entre elas perfazem a dimensão da interdisciplinaridade. Apostase que o trabalho, em parceria, irá resultar numa atuação docente mais significativa, contribuindo para a formação integral dos estudantes. Nessa direção, podemos apontar diversos estudos, como os de Freire (2016), Lemos (2019), Silveira (2019), bem como de Gomes (2020), que se propõem a analisar e compreender o PECM e os desdobramentos da inserção do professor de educação física na EI e nos anos iniciais do Ensino Fundamental no contexto da rede pública do DF.

A inserção do professor de educação física na EI, enquanto regente de um componente curricular obrigatório, consolida diversas contribuições ao desenvolvimento da criança. Acreditamos que é, por meio do corpo, que a aprendizagem se torna mais significativa. A criança, na EI, encontra-se em plena conquista de suas vivências de mundo usando o seu corpo. Tudo o que ela faz acontece primeiro no âmbito da experiência sensorial. Surge, então, uma necessidade de tornar essa experiência uma prática lúdica, envolvendo jogos, brincadeiras, músicas, danças, dramatizações etc. Sobretudo, as práticas vividas pela criança devem permear variados campos de experiências para que o desenvolvimento de diversas linguagens seja alcançado.

Segundo Ayoub (2001), a educação física, na EI, tem, na linguagem corporal, a sua base de trabalho, pois a criança, nessa etapa, brinca com o corpo e com o movimento. Porém, não é uma "propriedade" desse componente curricular. A linguagem corporal pode e deve ser trabalhada, também, em outros momentos da jornada educativa. Dessa forma, um trabalho integrado entre o professor de atividades e o professor de educação física é essencial.

Vale-se atentar para a qualidade desse trabalho integrado, ou seja, a forma com que realmente acontece. Para Buss-Simão (2005), existe a necessidade de compartilhar uma mesma concepção pedagógica e uma mesma abordagem educacional entre os professores de atividades e os professores de educação física. Não devemos fragmentar as funções entre eles, não devemos isolar esses profissionais em seus próprios campos, mas sim oportunizar a aprendizagem de uns com os outros. Atribuir importância ao trabalho desenvolvido, tanto dos professores de atividades quanto dos professores de educação física, é fundamental para o desenvolvimento de um trabalho interdisciplinar. E, para tal, é necessário que "o trabalho abarque não mais disciplinas ou profissionais 'disciplinados', mas sim as zonas de fronteira 
entre conhecimentos que possam ser apropriadas e dominadas por diferentes profissionais" (BARBOSA, 2006, p. 84).

Considerar a educação física inserida, na EI, nessa perspectiva, deve repercutir em ações pedagógicas integradas e interdisciplinares, pois a educação do corpo e seus movimentos é responsabilidade tanto dos professores de atividades quanto dos professores de educação física. Para que isso ocorra, é fundamental um trabalho compartilhado entre esses dois perfis profissionais. É imprescindível a realização de um projeto em parceria. Isso não significa que um deva ser melhor que o outro, ou que um precise se anular em função do outro. Ao contrário, o objetivo é conseguir reconhecer a especificidade do outro e fazer emergir um diálogo possível e de aproximação em relação à formação e aos conhecimentos de cada um. É necessário institucionalizar o trabalho coletivo. Assim, caracteriza-se a proposta do PECM, sendo este programa a base de construção do projeto que iremos descrever e analisar a seguir.

\section{GRUPO DE FORMAÇÃO E LITERATURA INFANTIL}

A instituição educacional em que se desenvolveu o projeto pedagógico em tela já abarca o PECM desde 2016. Entretanto, verificamos, por meio de um questionário respondido pelos professores, que a maioria deles não conhecia os princípios teóricos, os objetivos e a metodologia do programa. Dessa forma, foi necessário estruturar um grupo de formação ao longo do primeiro semestre de 2019, composto por 7 encontros, que se efetivaram no horário de coordenação pedagógica ${ }^{5}$. Entre os participantes, havia 19 professores de atividades e apenas um de educação física, totalizando 20 integrantes da mesma instituição. A ideia principal do grupo era tornar esses encontros um espaço-tempo de formação continuada. Ao longo do semestre, o grupo abordou diversos saberes, abarcando fundamentação teórica, currículo em movimento do Distrito Federal para $\mathrm{EI}^{6}$, PECM, interdisciplinaridade, entre outros. Sobretudo, tratou-se de um processo construído para viabilizar o planejamento, a execução e a avaliação de ações integradas e interdisciplinares entre os professores de atividades e de educação física, dando suporte ao trabalho voltado às crianças (Fotografia 1).

\footnotetext{
5 “A Coordenação Pedagógica constitui-se em um espaço-tempo de reflexões sobre os processos pedagógicos de ensino e de aprendizagem e formação continuada, tendo por finalidade planejar, orientar e acompanhar as atividades didático-pedagógicas, a fim de dar suporte ao Projeto Político Pedagógico" (DISTRITO FEDERAL, 2015 , p. 49). É um espaço-tempo previsto na carga horária de trabalho da SEEDF, ocorrendo em sua grande maioria no turno contrário de regência dos professores.

${ }^{6}$ Documento oficial da SEEDF, que oferece elementos para subsidiar as instituições de educação para a primeira infância na elaboração, desenvolvimento e avaliação de suas Propostas Pedagógicas. Esse documento alinha-se às Diretrizes Curriculares Nacionais para Educação Infantil - DCNEI e à Base Nacional Comum Curricular - BNCC, entre outros documentos legais (DISTRITO FEDERAL, 2018).
} 
Fotografia 1 - Primeiro encontro do grupo de formação com professores de Educação Infantil, realizado em 20 de fevereiro de 2019, no auditório da própria instituição educacional.

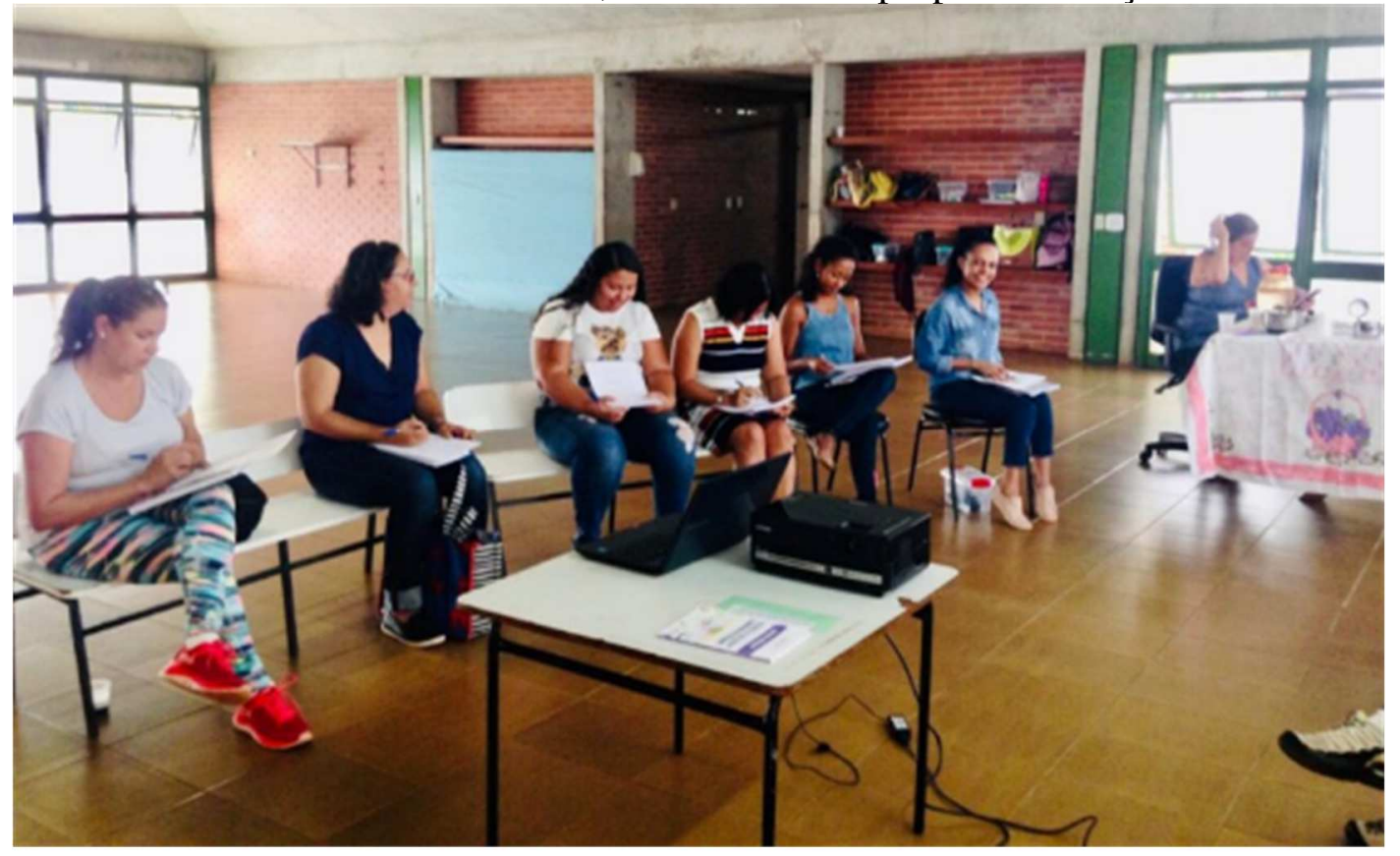

Fonte: Arquivo da pesquisa produzido pelas autoras.

Desde os primeiros encontros, surgiu a ideia de desenvolver o trabalho por meio de um projeto pedagógico. Uma das professoras relatou que se identificava com a prática de projetos e que acreditava ser facilitadora da interdisciplinaridade. Segundo ela, essa deveria ser uma metodologia predominante da EI. A partir disso, desencadeou-se uma proposta envolvendo a tríade "alimentação, higiene e valores", na qual seria tratado um elemento em cada mês, por todos os professores, concomitantemente. Com base nessa delimitação, o projeto foi intitulado "Por um mundo mais inclusivo e saudável: aprendendo valores, alimentando e cuidando do nosso corpo através de brincadeiras e histórias". O fio condutor das ações pedagógicas junto às crianças foi a literatura infantil, com base nos desdobramentos da VII Plenarinha ${ }^{7}$, que, no ano de 2019, teve o tema "Brincando e encantando com Histórias".

O intuito da proposta era ouvir os professores e torná-los parte de todo o processo de busca pelo conhecimento. Precisávamos considerar as características de cada um, o que eles pensavam a respeito, qual entendimento tinham da EI e do PECM. Para darmos seguimento à nossa intervenção, era relevante considerar as necessidades e as expectativas pessoais e profissionais, o contexto de trabalho e a cultura institucional na qual estavam inseridos. Os

\footnotetext{
${ }^{7}$ A Plenarinha é um projeto pedagógico ofertado pela SEEDF, que legitima o protagonismo infantil nas escolas públicas e parceiras do DF que ofertam EI e $1^{\circ}$ ano do Ensino Fundamental. Essa edição teve, como ênfase, o estímulo à literatura infantil.
} 
professores, apesar de não conhecerem com profundidade o PECM, possuíam alguma experiência de execução desse programa em seu cotidiano escolar. Tal saber pedagógico precisava ser valorizado e incorporado na construção de novos conhecimentos. A formação que buscávamos, nesse grupo, se assemelhava ao conceito trazido por Alvarado-Prada, Campos Freitas e Freitas (2010, p. 369), como sendo "um processo de aprendizagem que se realiza desenvolvendo-se individual e coletivamente dentro da cultura, incorporando-a, criando e recriando-a".

A literatura infantil faz parte da rotina escolar da primeira etapa da educação básica. Os professores de atividades usam esse recurso constantemente. São inúmeros os benefícios que o livro literário pode desempenhar no dia a dia de uma instituição de EI. Entre eles, podemos destacar o estímulo à criatividade, o desenvolvimento da linguagem, o despertar do senso crítico, as brincadeiras de faz-de-conta, a promoção da construção de valores e conceitos, a contribuição na formação da personalidade da criança e o estímulo ao envolvimento social e afetivo. Estes aspectos favorecem o aprendizado e incentivam o prazer pela leitura (SOUZA; DALLA BERNARDINO, 2011).

Os livros infantis que nortearam as ações do projeto se caracterizavam tanto por histórias de cunho informativo como por narrativas originais e divertidas. Em suas histórias, alguns livros apresentavam diferentes situações cotidianas a respeito dos assuntos abordados, enquanto outros traziam histórias fictícias, explorando o imaginário infantil. Nesse sentido, a literatura infantil se tornou uma excelente estratégia didática, pois alcançava as crianças ao mesmo tempo que permitia que os professores abordassem os temas norteadores. Desse modo, foi selecionado um conjunto de 12 livros infantis, sendo um para cada semana, preenchendo, assim, os três meses do cronograma das atividades (Fotografia 2). 
Fotografia 2 - Coleção de livros infantis que mediaram o projeto pedagógico.
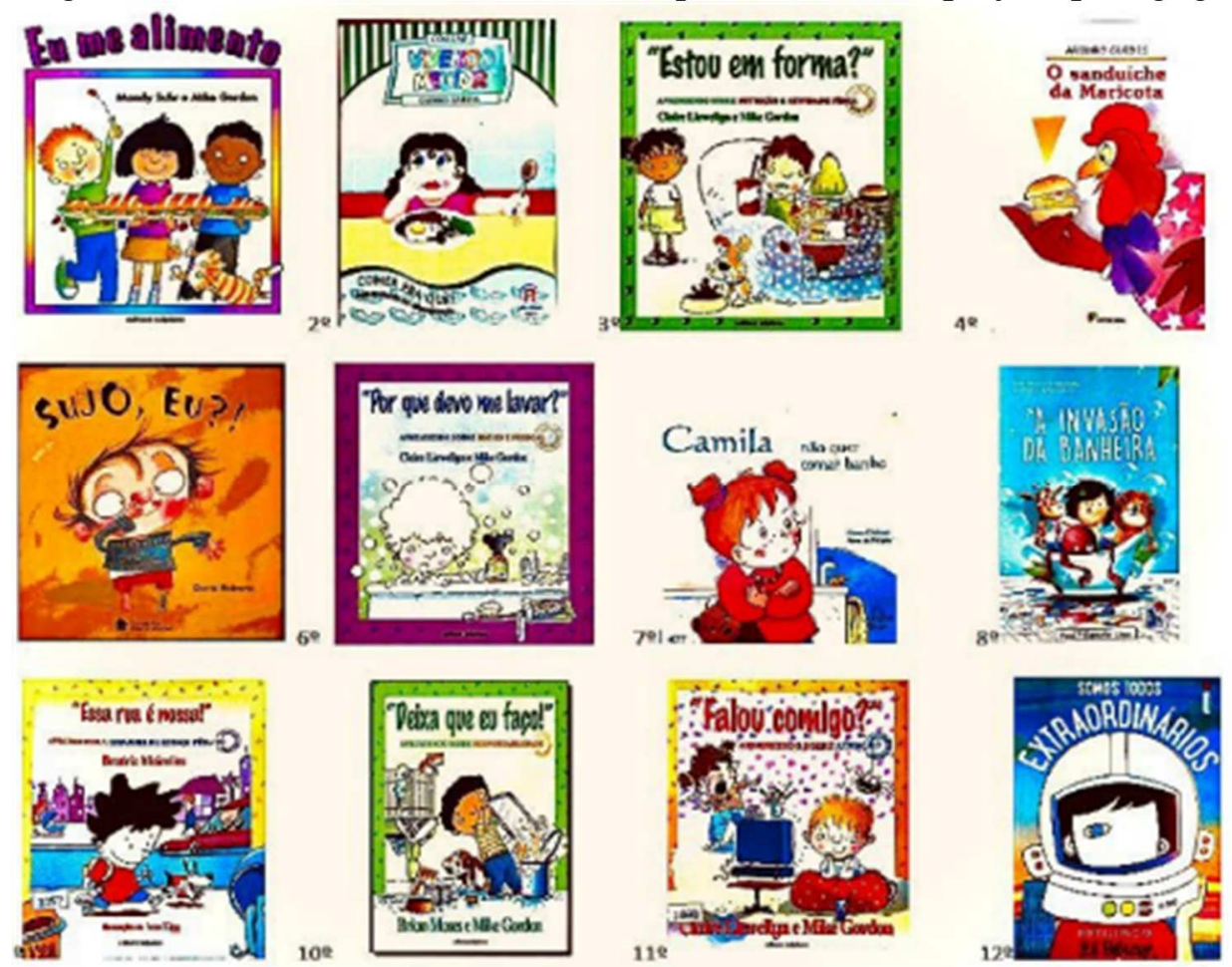

Fonte: Arquivo da pesquisa produzido pelas autoras.

A professora de educação física ficou responsável pela leitura dos livros para as crianças, uma vez que tinha contato com todas as turmas. Isso resolveu o problema de termos, apenas, um exemplar de cada livro. Todavia, tanto a professora de educação física como os de atividades realizaram diferentes brincadeiras e jogos a partir dessas histórias. Houve, também, por parte dos professores de atividades, a promoção de outros objetivos pedagógicos, como a exploração de diferentes linguagens presentes no currículo. Por sua vez, a professora de educação física deu ênfase a aspectos próprios ao conteúdo específico desse componente, como jogos, brincadeiras, danças, ginásticas, esportes, entre outros.

Destacamos, abaixo, algumas falas dos professores que valorizaram a utilização do livro de história como recurso pedagógico. As avaliações foram unânimes ao apontar que a literatura infantil facilitou o diálogo entre os professores e auxiliou na organização das atividades a serem executadas em conjunto:

Facilitou muito com essa relação entre os conteúdos do dia a dia e da educação física, pude saber o que seria trabalhado no momento da aula de educação física, assim, uma aula reforçou a outra e pudemos expor o mesmo assunto com diferentes abordagens, dinâmicas e opiniões (A $\left.4^{8}, 03 / 07 / 19,7^{\circ} \mathrm{GF}\right)$;

\footnotetext{
${ }^{8}$ Preservando a identidade dos professores-participantes, os identificamos com a letra “A”, seguida da numeração
} 
Acredito que por se tratar de Educação Infantil a linguagem literária é a que mais atinge com grande sucesso para se conseguir os objetivos e se fazer a interdisciplinaridade entre diversos temas (A10, 03/07/19, $\left.7^{\circ} \mathrm{GF}\right)$;

Gostei muito de ter um livro (história) como tema interdisciplinar para explorarmos várias linguagens. A riqueza de possibilidades foi proporcionada ficando dependente apenas da criatividade dos professores [...] As histórias são parte da rotina diária na Educação Infantil, o que do meu ponto de vista, facilitou a interdisciplinaridade. (EF, 03/07/19, $7^{\circ} \mathrm{GF}$ ).

Apesar das experiências positivas relatadas, é importante reconhecer a dificuldade que os professores enfrentaram para efetivar a interdisciplinaridade por meio da literatura infantil. Existia uma preocupação real em como transpor a temática do livro para o conteúdo específico necessário para o desenvolvimento das crianças na EI. Além disso, os professores de atividades começaram a sentir falta do livro físico em sala. Era importante tê-lo à mão para uma releitura ou para dar um novo enfoque à história, por meio de outras atividades, além de oportunizar o manuseio do material por parte das crianças. Com isso, passamos a disponibilizar a forma digital do livro para aqueles professores que precisassem usá-lo em sala de aula.

O fato de a professora de educação física ser a leitora dos livros nos trouxe outra dificuldade. Ela não tinha o costume de contar histórias para as turmas da mesma forma que os professores de atividades faziam. Várias dúvidas se apresentaram, como, por exemplo, a forma de posicionar os alunos para ouvirem a história; a forma de explorá-la após a contação; o momento ideal para a atividade; a entonação da voz; as diferentes formas de se contar. Por causa dessa dificuldade, o início do projeto foi um pouco tumultuado, pois o momento da leitura do livro infantil representava um desafio. A própria professora de educação física realizava experimentações e solicitava dicas aos professores de atividades. Aos poucos, notamos que o domínio, com mais destreza, desse momento foi acontecendo, o que estimulou à integração (Fotografia 3).

de 1 a 19 para cada professor de atividades. Para a professora de educação física, utilizamos a sigla EF. 
Fotografia 3 - Leitura do livro pela professora de educação física, com participação do professor de atividades. De modo geral, as crianças demonstraram interesse e atenção pela

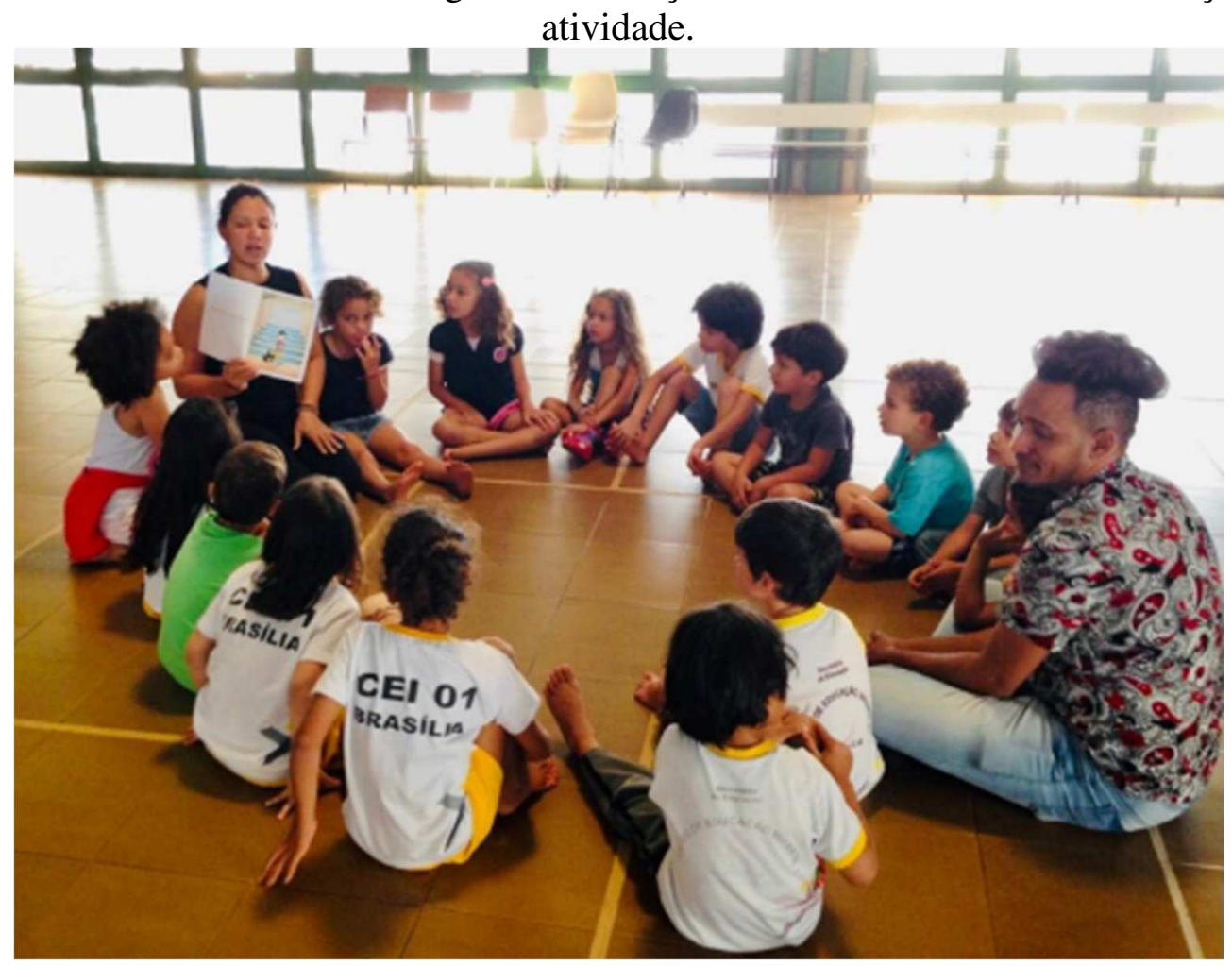

Fonte: Arquivo da pesquisa produzido pelas autoras.

Com efeito, a cada aula que era aplicada, evidenciava-se um momento de aprendizagem para os professores participantes do projeto. O grupo de formação permaneceu atuando em conjunto durante a realização das intervenções com as crianças, aspecto que favorecia a discussão em termos de avaliação. Debatiam-se os desafios, as eventuais dificuldades e, também, as novas possibilidades segundo as experiências de cada um. Ressaltamos que essas dificuldades, aqui dispostas, eram avaliadas e refletidas ao longo do processo. Esse espaçotempo foi essencial para o amadurecimento do grupo de professores em relação às atuações docentes. Conforme anteriormente assinalado, investimos na formação continuada dos educadores dessa instituição. Esperávamos que o grupo pudesse ser capaz de, a partir desses momentos de reflexão, reorganizar as ações pedagógicas que estavam ocorrendo. Para Silva e Ribeiro (2020), o professor, no seu processo de formação docente, precisa pensar e refletir sobre a sua própria prática e deve procurar estabelecer relações teóricas e práticas constantemente.

Outro ponto importante que se evidenciou, na fala dos professores, relaciona-se à sua própria formação inicial. Como desenvolver ações pedagógicas integradas e interdisciplinares se foram formados em perspectiva fragmentada e sem conexão entre uma disciplina e outra? 
Pereira (2004) destaca que o conhecimento adquirido, na formação inicial, tende a ser desprovido de conexão com a realidade concreta, pois aprendemos por meio de um ensino técnico e instrumental, no qual predominam saberes isolados.

A própria instituição, no contexto de trabalho desses professores, segue uma cultura de fragmentação dos "conteúdos". Os professores relataram, no grupo de formação, que é recorrente organizar as linguagens, distribuindo-as nos tempos pedagógicos. Ou seja, divide-se a linguagem matemática e a linguagem de leitura e escrita entre os professores, de acordo com a regência no turno matutino e vespertino nas turmas de regime integral. Além disso, entendese que o trabalho cognitivo deve ser realizado, em sala de aula, com os professores de atividades, e o trabalho corporal, com a professora de educação física. Desenvolver esse projeto pedagógico, portanto, nos requisitou um esforço maior, buscando ir além do trabalho disciplinar habitual.

Considerando que os professores não foram preparados para trabalhar com a interdisciplinaridade e não tiveram experiências concretas de ações pedagógicas nessa perspectiva, irão encontrar desafios que requerem esforços individuais e, ao mesmo tempo, colaboração coletiva (PEREIRA, 2004). A aprendizagem, por conseguinte, ocorrerá por meio dos acertos/erros no processo de intervenção e aplicação dos programas. Nesse sentido, durante o acompanhamento do grupo de professores, foi possível registrar falas que confirmaram a importância desse espaço de formação. O diálogo é a ferramenta essencial para o desenvolvimento de ações pedagógicas integradas e interdisciplinares - uma perspectiva do projeto em tela.

Seguem, abaixo, algumas falas dos professores-participantes que consideramos importantes, pois mostram a ressignificação das ações pedagógicas relacionadas ao PECM a partir da participação no grupo de formação.

Mudou minha compreensão sobre a proposta/projeto que não via como interdisciplinar, apenas como uma aula à parte. O compromisso de estabelecer uma parceria, tanto no planejamento quanto na prática, trocando ideias e trazendo sugestões (A2, 03/07/19, $7^{\circ} \mathrm{GF}$ );

Minha prática pedagógica incorporou o campo de experiência do corpo, gestos e movimentos não só isoladamente, mas interagindo com os outros campos de experiência do currículo da EI [...] A prática pedagógica diária se tornou mais interdisciplinar e não tão segregada como antes. Maior interação com os colegas e o profissional de educação física. Desenvolveu, melhor, recuperei a necessidade de pesquisa, estudo no planejamento das aulas (A10, 03/07/19, $\left.7^{\circ} \mathrm{GF}\right)$; 
Mudou como percebo o movimento e a necessidade de integração das diversas áreas em uma mesma atividade. $\mathrm{O}$ corpo e o movimento não se dissociam do letramento, por exemplo (A14, 03/07/19, $7^{\circ} \mathrm{GF}$ ).

Observei os professores mais atentos e curiosos sobre como seria o procedimento nas minhas aulas, obtive solicitações e troquei informações previamente com alguns professores. Alguns professores passaram a atuar mais proativamente nas aulas. Eu tive que pesquisar mais e estudar os temas abordados, passei a ouvir mais as crianças (os alunos) dando ênfase a outros campos de experiência não somente a parte motora. Passei a interagir mais com os professores (EF, 03/07/19, $\left.7^{\circ} \mathrm{GF}\right)$.

Tais falas evidenciam a necessidade do espaço-tempo de formação conjunta, assim como a importância do diálogo nesse processo. Por mais que nossa experiência tenha sido, de forma geral, bem-sucedida, ainda precisamos enfrentar discussões pertinentes ao funcionamento do PECM. Quando o programa chega à escola, carrega, consigo, um sistema de organização disciplinar e acaba por provocar - mesmo que não deliberadamente - a fragmentação de espaços-tempos de aula. Isso pode ser percebido no segundo princípio de funcionamento do PECM.

O desenvolvimento do Programa, quanto ao quantitativo e duração das aulas, na Educação Infantil e nos Anos Iniciais do Ensino Fundamental será organizado assim: duas intervenções semanais de 50 minutos cada, evitandose aulas duplas ou em dias consecutivos (DISTRITO FEDERAL, 2019, p. 23).

Esse é um paradoxo importante que precisa ser esclarecido do ponto de vista interdisciplinar. Quando o programa aponta em si essa formatação, automaticamente, em nosso pensamento formado numa perspectiva fragmentada, passamos a acreditar que cada professor irá realizar seu trabalho em seu momento, em seu espaço, do seu jeito e de forma separada. Porém, Thiesen (2008, p. 5) nos revela e nos ajuda a entender que as abordagens teóricas sobre as práticas interdisciplinares "não põem em xeque a dimensão disciplinar do conhecimento em suas etapas de investigação, produção e socialização". Nesse sentido, devemos ter um olhar para as disciplinas a partir de um diálogo, de uma troca, de uma integração conceitual e metodológica. Ou seja, por mais que as configurações do PECM se apresentem dessa forma, o que precisa mudar, no cotidiano escolar, é o nosso entendimento, a nossa forma de pensar, executar e avaliar esse programa. Ratificando, então, a importância de a formação dos professores acontecer, também, de forma integrada e interdisciplinar.

Da mesma forma, Japiassu (1976) afirma que a atividade interdisciplinar pode promover uma ligação entre as fronteiras das disciplinas, funcionando como uma ponte. Ao mesmo 
tempo, assegura o seu caráter próprio, seus modos particulares e seus resultados específicos. Transpondo tal ideia para a realidade de nossa experiência, podemos concluir que o professor de educação física não vai deixar de dar aula de educação física para assumir o papel do professor de atividades, tampouco o contrário deve acontecer. Tanto um quanto o outro devem integrar às suas atividades um conjunto de conhecimentos pertinentes aos seus objetivos pedagógicos. Isso requer uma relação dialógica entre os professores como condição para que a interdisciplinaridade aconteça. As ações pedagógicas integradas e interdisciplinares representam um eixo central do PECM. São elas que promovem a qualidade da inserção do professor de educação física na EI e nos anos iniciais do Ensino Fundamental. Gomes (2020) reforça a importância da construção curricular e do trabalho coletivo nas instituições escolares da primeira infância. Tais apontamentos são vistos, em sua pesquisa, como imprescindíveis para a concretização das ações pedagógicas interdisciplinares nesse programa da rede pública do Distrito Federal.

\section{CONSIDERAÇÕES FINAIS}

A experiência interventiva nos provocou a pensar em possibilidades de ações pedagógicas integradas e interdisciplinares entre professores da EI. Neste caso específico, utilizamos a literatura infantil e o grupo de formação como possibilidade de facilitá-las. A literatura infantil permitiu a unicidade do conhecimento que estava sendo disponibilizado às crianças. As ações pedagógicas, tanto dos professores de atividades quanto da professora de educação física, eram articuladas a partir do tema da história da semana. Isso fez com que os professores compartilhassem um interesse em comum, fomentando o diálogo entre eles. $\mathrm{O}$ grupo de formação, por sua vez, garantiu a elaboração, o acompanhamento e a consolidação de uma proposta integrada, considerando todas as etapas do projeto.

Essa experiência também nos fez repensar o papel do professor da EI. Entendemos que o professor, nesse contexto da Educação Básica, independentemente da sua formação específica, precisa investir em ações pedagógicas em consonância com as características desta etapa educacional. O professor de educação física, quando se insere na EI, precisa ter ciência de que ele se torna um professor da EI, assim como seus demais pares, os professores de atividades. A educação física deve dialogar com um projeto pedagógico da instituição, assim como qualquer outra área de conhecimento que se traduza em saber escolar. Isso não diminui seu valor e nem fragiliza sua legitimidade. Talvez, isso até reforce sua inserção do ponto de 
vista político, uma vez que sua chegada, na EI, não rivaliza com a pedagogia. A contribuição de profissionais que podem dialogar e que conseguem, a partir de sua especificidade, somar e se integrar, é extremamente significativa. Observamos, em nossa experiência, que esse diálogo favorece a aprendizagem e o desenvolvimento das crianças.

Precisamos nos esforçar para transformar o cotidiano escolar por meio da mudança de significado que atribuímos às disciplinas escolares. Embora não devamos negá-las, podemos construir uma integração conceitual e metodológica entre elas. Se conseguirmos isso, estaremos mudando a nossa forma de planejamento, execução e avaliação das ações pedagógicas, transformando, portanto, a EI.

\section{REFERÊNCIAS}

ALVARADO-PRADA, L. E.; CAMPOS FREITAS, T.; FREITAS, C. A. Formação continuada de professores: alguns conceitos, interesses, necessidades e propostas. Revista Diálogo Educacional, Curitiba, v. 10, n. 30, p. 367-387, maio/ago. 2010.

AYOUB, E. Reflexões sobre a Educação Física na Educação Infantil. Revista Paulista de Educação Física, São Paulo, n. 4, p. 53-60, 2001.

BARBOSA, I. G. Educação infantil: o lugar da pedagogia e da educação física em uma perspectiva sócio-histórico-dialética. Pensar a Prática, Goiânia, v. 5, n. 1, p. 71-91, 15 nov. 2006.

BRASIL. Lei $\mathrm{n}^{\circ}$ 9394, de 20 de dezembro de 1996. Estabelece as diretrizes e bases da educação nacional. Diário Oficial da União: seção 1. Brasília, DF, p. 27833, 23 dez. 1996. Disponível em: http://www.planalto.gov.br/ccivil_03/leis/19394.htm. Acesso em: 26 fev. 2021.

BUSS-SIMÃO, M. Educação física na educação infantil: refletindo sobre a "hora da Educação Física". Motrivivência, Florianópolis, ano 17, n. 25, p. 163-172, dez. 2005.

DISTRITO FEDERAL. Secretaria de Estado de Educação. Regimento Escolar da Rede Pública de Ensino do Distrito Federal. 6. ed. Brasília, DF: SEEDF, 2015. Disponível em:

https://agenciabrasilia.df.gov.br/wp-conteudo/uploads/2016/10/regimento-escolar-rede-publica-deensino-df.pdf. Acesso em: 26 fev. 2021.

DISTRITO FEDERAL. Secretaria de Estado de Educação. Currículo em movimento da Educação Básica: educação infantil. 2. ed. Brasília: SEEDF, 2018

DISTRITO FEDERAL. Secretaria de Estado de Educação. Educação com Movimento: Programa de inserção do professor de Educação Física na Educação Infantil e nos Anos Iniciais do Ensino Fundamental. Brasília, DF: SEEDF, 2019.

FREIRE, J. O. Educação Física escolar em Brasília: análise comparativa de currículos dos anos iniciais do ensino fundamental. 2016. 131 f. Dissertação (Mestrado em Educação Física) Universidade de Brasília, Faculdade de Educação Física, Brasília, 2016.

GOMES, A. P. L. A educação física e a interdisciplinaridade na infância: um estudo sobre o Programa Educação com Movimento da Secretaria de Estado de Educação do Distrito Federal. 2020. 141 f. Dissertação (Mestrado em Educação Física) - Universidade de Brasília, Faculdade de Educação Física, Brasília, 2020.

IMPOLCETTO, F. M.; DARIDO, S. C. Educação física como componente curricular da Educação Básica: aspectos legais. In: ALBUQUERQUE, D. I. P.; DEL-MASSO, M. C. S. Desafios da educação física escolar: temáticas da formação em serviço no PROEF. São Paulo: Cultura 
Acadêmica, 2020. p. 14-27.

JAPIASSÚ, H. Interdisciplinaridade e patologia do saber. Rio de Janeiro: Imago, 1976.

LANKSHEAR, C.; KNOBEL, M. Pesquisa Pedagógica do Projeto à Implementação. Tradução de Magda França Lopes. Porto Alegre: Artmed, 2008.

LEMOS, G. P. A Educação Física na Educação Infantil do Distrito Federal: uma experiência em construção. 2019. 148p. Dissertação (Mestrado em Educação Física) - Universidade de Brasília, Faculdade de Educação Física, Brasília, 2019.

MAGALHÃES, J. S.; KOBAL, M. C.; GODOY, R. P. Educação física na educação infantil: uma parceria necessária. Revista Mackenzie de Educação Física e Esporte, Campinas, v. 6, n. 3, p. 4352, 2007.

PEREIRA, R. R. A interdisciplinaridade na ação pedagógica do professor de educação física da Rede Municipal de Ensino de Porto Alegre. 2004. 247 f. Dissertação (Mestrado em Ciências do Movimento Humano) - Universidade Federal do Rio Grande do Sul, Escola de Educação Física, Porto Alegre, 2004.

SILVA, J.; ARCE, A. Infância, conhecimento e função docente nos documentos do MEC destinados à educação infantil: uma análise a luz da psicologia histórico-cultural. Revista HISTEDBR, Campinas, n. 39, p. 119-135, set. 2010.

SILVA, N. S.; RIBEIRO, A. M. B. Formação docente: notas sobre professor pesquisador e professor reflexivo. Revista Didática Sistêmica, v. 22, n. 1, p. 96-107, 2020.

SILVEIRA, E. R. Prática pedagógica da educação física na Educação Infantil: uma análise dos portifólios do projeto educação com movimento no Distrito Federal. 2019. 105 f. Dissertação (Mestrado em Educação Física) - Universidade de Brasília, Faculdade de Educação Física, Brasília, 2019.

SOUZA, L. O.; DALLA BERNARDINO, A. A contação de histórias como estratégia pedagógica na educação infantil e ensino fundamental. Educere et Educare, v. 6, n. 12, p. 235-249, jul./dez. 2011.

THIESEN, J. D. S. A interdisciplinaridade como um movimento articulador no processo ensinoaprendizagem. Revista Brasileira de Educação, Rio de Janeiro, v. 13, n. 39, set./dez. 2008. 